\title{
Disaster Preparedness in Nepal: Insights and Observations from Literature and Field Work
}

\author{
Karvinen Ikali \\ Leadership and Service Systems Competency Area, Diaconia University of Applied Sciences, Helsinki, Finland
}

\section{Email address:}

ikali.karvinen@diak.fi, ikali.karvinen@icloud.com

\section{To cite this article:}

Karvinen Ikali. Disaster Preparedness in Nepal: Insights and Observations from Literature and Field Work. Science Journal of Public Health. Vol. 3, No. 1, 2015, pp. 138-142. doi: 10.11648/j.sjph.20150301.32

\begin{abstract}
Nepal is one of the poorest countries in the world and due to historical and geographical reasons it is vulnerable to various emergencies and disasters. The aim of this research was to find out how the research literature describes the disaster preparedness and emergency response in Nepal and how one can observe them in the chosen daily context in the Balkhu settlement in Nepal. This research is based on a descriptive literature review as well as interviews and observations. The descriptive review was conducted with the databases Cinahl fulltext, Ebsco Academic Search Premier and ASP. The information from the literature was grouped to thematic categories by content analysis. The categories facilitated the process of developing an interview and observation guide. Empirical data was collected by interviews and observations in the Balkhu settlement and the results were grouped into the same categories that were found in the literature. Results from this research suggest that leadership is important in building up the institutional capacity for disaster preparedness in Nepal. Disaster preparedness plans should more precisely cover even the psychosocial support of disaster victims. At the local level, empowerment of women and multi-sectorial co-operation are needed. In the chosen Balkhu community, not much is done for disaster preparedness. It is recommended that a general awareness of disaster preparedness and the training of residents be included as components to the ongoing development projects in that community.
\end{abstract}

Keywords: Nepal, Kathmandu, Disasters, Preparedness

\section{Introduction}

Emergency preparedness and response is an area which requires a multi-professional and multi-agency approach. Ablah et al. [1] found that, at the local level in the United States, effective collaboration is required between community health centers and local health departments to enhance the quality of disaster preparedness training and response. Moreover, globally some locations are more vulnerable to disasters than others due to historical, traditional, economical or geographical reasons, and response to the challenges might be even more complicated in these places. In this study we focus on one of the most vulnerable locations in the world, Nepal.

Nepal is one among the poorest countries in the world and it is highly vulnerable to a variety of disasters. Nepal is situated in South Asia and shares borders with China and India. The population of Nepal is approximately 29000000 . The majority of the population lives in central highlands and in rural areas. [2] The capital city of Nepal, Kathmandu, is a rapidly expanding urban area with a growing number of health and environmental hazards. Among many others, water and air pollution can be reported. [3] Environmental hazards are severe specifically among those who live in informal settings [4].

In earlier research Doocy et al. [5] found that normally, in a developing country context, households and communities are unprepared for any disaster response. They considered that an expansion of both community-based disaster preparedness programmes and study of their evidence should be prioritized in developing work. Disaster survivors do not need only physical and social support. North and Pfefferbaum [6] remind us in their paper that, in post-disaster settings, systematic mental-health case-identifications, triage classifications and interventions are needed in emergency and trauma response.

This study focuses on the disaster preparedness in Nepal generally and in the Kathmandu area specifically. The author 
became interested in the topic while having the opportunity of participating in an international programme (GLORE) focused on vulnerable communities in Nepal. The study was a part of a larger Global Responsibility project. This study involves two stages. First, it is based on a descriptive literature review, and second, it is founded on the empirical data that was collected through qualitative methods such as interviews and observations.

\section{Materials and Methods}

The objective of this study is to examine the overall disaster planning and disaster preparedness in Nepal. The aim of this research is to produce material for disaster planning purposes in Nepal in general and also more specifically for the chosen Balkhu Settlement.

The research questions guiding this work were:

1. How does the chosen literature describe the disaster preparedness and emergency response in Nepal?

2. How can one observe them in the in the chosen daily context in the Balkhu settlement?

Two different designs were used to approach the disaster risk preparedness and emergency response in Nepal: literature review and empirical, qualitative data collection through methods such as interviews and observation.

At the first stage, the descriptive literature review with systematic searching methods were followed loosely. The descriptive literature review was conducted in August and December 2014 with the data-bases of Cinahl fulltext, Ebsco Academic Search Premier and ASP. In total 18 articles were found from scientific databases by using different combinations of the keywords. As many as 11 of them were applicable to this study. Search terms included keywords of Emergency Preparedness, Disasters, Kathmandu and Nepal. The literature search was made in two cycles: at the beginning of the process and again at the end of the study to obtain more comprehensive literature of the disaster preparedness in settlements in developing countries. The analysis of the literature review was done by content analysis by grouping the data from the articles into thematic categories. Three major categories were found: 1 . Institutional capacity on disaster risk reduction, 2. Psychosocial support in disaster preparedness and 3 . Geographical, community and local-level disaster risk practices.

After the literature review at the beginning of the study, a combined observation and interview guide was designed. The guide was based on the above-mentioned categories derived from literature. The observation objectives and interview questions were based directly on information from the articles. The empirical data was collected by observations and interviews at the Balkhu settlement in Kathmandu, Nepal, in October and November 2014. The researcher travelled to the settlement as a part of the intensive study programme with a group of students and a fellow researcher who had the special task of finding ways to support vulnerable communities in Nepal. The researcher conducted this study beside the other activities he had at the settlement with the students. The interviews and observations were conducted simultaneously using the interview and observation guide. In order to avoid duplicate questioning, the interview material was partly collected from interviews conducted by students and fellow researcher s. The interviews were conducted in informal settings for two key informants who worked and lived in the settlement. In order to gain a deeper understanding of the general disaster preparedness in Nepal, an interview in the local hospital and one group interview in the settlement was also organized but that data was used only as background information. Important data was also obtained from a student who worked in the settlement as a voluntary worker. Observations were made in various locations in the Balkhu settlement. They were documented by writing them down in a notebook or on an observation form with short notes. Another way to document observations was photographing the surroundings. This field study had features typical of an ethnographic study.

\subsection{The Research Location}

The empirical data for this research was gathered at the Balkhu settlement, located in the Lalitpur area, near the city center of Kathmandu, Nepal. The Balkhu settlement is a slum area with informal housing on the banks of the river Bagmati in Balkhu. The land is occupied by its inhabitants illegally and the residents do not own the land. It is estimated that the area contains approximately 400 households. The residents are mostly engaged in labor under informal agreements. The area itself is constructed without any formal planning and its facilities and infrastructure are very poor. The facilities at the slum include churches, a school and public toilet areas. The leadership of the area is 'formally' elected by the residents. The residents of this settlement have a daily struggle with food, electricity and water.

\subsection{The Ethics Statement}

The official research permission was given by the university of applied sciences where the researcher is employed (Diaconia University of Applied Sciences). Since the research was a part of a larger intensive programme in Nepal, organized by the local college as a part of larger international project, no other permissions were needed.

\section{Results}

\subsection{Results Based on the Literature}

\subsubsection{Institutional Capacity of Disaster Risk Reduction}

According to the literature, leadership is crucial in building the capacity for disaster risk reduction. Filmer et al. [7] report that in non-governmental health facilities in Nepal, the institutional leaders struggle to apply the disaster plans in the face of spontaneous disasters. It was found that in a disaster situation, multiple people easily assume the role of leader and contradictory commands are given. It was also reported that leaders often are rather observers than participants and avoid 
any hands-on work. Filmer et. al recommend the establishment of both clinical and non-clinical roles for leaders in crisis situations in Nepal to enhance the capacity of disaster preparedness in health settings. Pre-hospital care should play a major role in this process [2].

Different institutions can build institutional capacity in society to make it better prepared for disasters. Preparedness needs to be seen as a multi-sectorial challenge. The role of school organizations at all levels is important in disaster education in Nepal. According to Shiwaku et al. [8] the Nepalese school disaster education can raise the perception of risk but cannot empower students to understand pre-disaster measures and to take any actions for disaster reduction. On the other hand, self-education was reported to be an effective way to educate students concerning the importance of implementing disaster measures. Furthermore, Shiwakul et al. remind us that the community has an important role in that it can promote the role of students as tools for actual disaster risk reduction. In the future, disaster training in the schools in Nepal should be based on active learning and community involvement.

\subsubsection{Psychosocial Support in Disaster Preparedness}

According to Acharya, Upadhya and Kortmann [9], Nepal is a psychosocially vulnerable country not only due to its high risk of natural disaster but also due to its historical roots containing prolonged civil conflicts. Still, the national Health Sector Emergency and Disaster Response Plan does not address mental health or psychosocial support directly. In their article, Achary et. al suggest that mental health support should be included in the disaster plans in Nepal in the form of social and psychological interventions and development of community mental health services. Moreover, the disaster preparedness plans should be more precise. The integration of mental health and psychosocial support into other services is needed. In their editorial, Bolton, Tol and Bass [10] also remind us that not only should practitioners pay more attention to psychosocial support but they should also take more interest in evaluating methods and suitable tools to measure their practice in complex emergencies. The pluralist approach to psychosocial support was applied e.g. in a case study by Kohrt [11], who uses two different approaches to understand vulnerability in Nepal. Both epidemiologic data and policy reviews were used by him to present how the caste system impacts health and wellbeing negatively.

In our literature review, we found one very specific article about psychosocial rehabilitation for torture victims [12]. Even though the article remains irrelevant when we examine the psychosocial support in disasters in general in Nepal it highlights an important issue of underlying political issues in mental health services. According to Sassene and Triantafillou, for example, the psychosocial therapy available at the Center for Victims of Torture in Nepal is trying to make victims of torture "align their personal desires and freedom with the political objectives of turning Nepal into a liberal democracy." The offered therapy is, according to the authors, explicitly linked to a wider political strategy pursued by the Nepalese government and other donors.

\subsubsection{Geographical, Community and Local-Level Disaster Risk Practices}

Local level governance for disaster preparedness has attracted a great deal of attention during the past years. In their research, Jones, Arayal and Collins [13] examined the two Risk and Resilience Committees (RRCs) that were established in Nepal as a part of larger action research. One of these operates in Panckhal and the other in Dhankuta. According to the study, the most sufficient way at the community level for risk reduction in Nepal is close interaction with local governments. It was also found that strong leadership, possibilities for further funding and eliciting elite control over the desired functions were the key issues to pay attention to in local level practices for governance of risk and resilience in Nepal.

Moreover, Dhungel and Ojha [14] underline women's empowerment for disaster risk reduction and emergency response in Nepal. According to the authors, social taboos and norms restrict women's freedom to express their needs for humanitarian workers in crises. One solution for this has been the Disaster Risk Reduction and Humanitarian Programme (DRR-HP) which has a component of women's empowerment. This has led to the establishment of 42 Women's Empowerment Centers which form, according to the study, a successful way to reduce women's vulnerability in these communities. The centers have several activities, such as protecting agricultural land, lobbying against destructive practices and identifying vulnerable members of the community, among others. The programme has a positive impact on women's leadership in the community.

Although in this research the main focus has been on disaster risk reduction on a general level, one article on specific interventions of care-seeking practices was chosen for the review. Syed, Khadka, Khan and Wall [15] studied the care-seeking practices in South Asia to save the newborn lives and they included data from Nepal in their study. The study shows that access to antenatal care in Nepal is limited. Furthermore, seeking care for maternal danger signs from qualified health care providers was rare. Postnatal care was almost nonexistent due to the underlying traditional beliefs of women's uncleanliness during the postpartum period. In addition, understanding of newborn babies' danger signs was poor due to family traditions and the lack of knowledge, economical assets and transportation. Such underlying hindrances for general disaster preparedness might be similar to those which hinder care-seeking in general.

\subsection{Results from the Empirical Material}

\subsubsection{Preparations for Disaster}

Generally it was found that the Balkhu settlement is poorly equipped for disasters. The low preparation level was accompanied with a poor understanding of general safety concerns. Still, some general safety plans for evacuation purposes were made, according to our informants. In case of a fire, for example, the community trusts its own residents. 
All members are called to help in such an event. Still, the lack of equipment such as fire extinguishers is evident. Since the settlement is illegal, not much was done by the local authorities or the government to enhance disaster preparedness in this particular community. On the contrary, the government's intention has been to re-settle the residents in another location but it has not been possible due to the resistance of the people in that particular community. In the observation notes, this is stated as follows:

"As the settlement is illegal it raises the genuine and constant fear and psychosocial vulnerability in the community. The policy level activities had already taken place but contradictory have not had effect at the political level yet." (Observation notes 11/2014)

\subsubsection{Health and Psychosocial Aspects of Disaster}

According to the general observations, many health-related hazards could be reported at the Balkhu settlement, including traffic-related, sanitation-related and environment-related hazards. Specifically, it was reported that cases of family violence could be found, causing health problems. On the other hand, strong psychosocial support was found to be a protective factor. General and religious activities, for instance, organized by local churches and voluntary organizations were important for general safety and well-being:

"Surprisingly the social structure at the community is well-organized and the resident have lots of social support in terms of primary schooling, faith-based activities and mutual understanding between residents..." (Observation notes 11/2014)

The role of spiritual support cannot be underestimated since some of the most important stakeholders in the community were faith-based organizations. Insecurity is not only increased by the economic challenges but also by the constant fear of authorities who try to decompose the slum. Unemployment and constant lack of basic needs have, in many cases led to a situation in which the support of the family does not exist any longer due to employment outside the community or even outside the country. According to our key informant, stories of human trafficking had been heard.

\subsubsection{Geographical Hazards at the Community}

The given location at the river bank made the settlement itself a hazard for the environment:

"The given location at the bank of the river makes nature vulnerable around the settlement. One can easily observe that public toilets and open latrines challenge the environment" (Observation notes 11/2014)

One can observe that public toilets and latrines are located next to the river and no waste-water sewer can be found. The geographical area of the settlement is limited by main roads and the river, leaving a very limited space for living and gardening. Narrow streets, sharp corrugated iron eaves at the low level and rough paths cause a risk of injury. It was mentioned that, fortunately, no flooding or landslides are reported to have taken place in this particular area during recent times.

\section{Discussion}

"There are some relations between disaster and poverty.--The economic progress needs to be evenly distributed within the cross-section: emphasis on the poor, marginalized and underprivileged is the core of the democratic base of development. ---Disaster risk is part of the dynamic forces which construct the process of development." (Shrestha11.11.2014 [17])

In this research, the results of the literature review highlight the institutional capacity building for disaster risk reduction. Also, psychosocial support as a part of disaster preparedness is strongly recommended. Both of these aspects are supported by earlier research by e.g. North and Pfefferbaum [6] and Doocy et Al. [5]. It was found that a crucial component of institutional capacity building is well-functioning leadership. The literature suggests the strengthening of geographical, community and local-level disaster risk practices [13]. At the local level, empowerment of women as well as multi-sectorial co-operation is needed. In the Balkhu settlement the strengthening of the disaster preparedness practices could be started by small steps. Empowerment of the residents, awareness education and co-operation among different stakeholders would play a major role at the beginning. Support from the local and central government is needed. Medical and fire-services, in other words, the necessary rescue readiness, should be seen as a part of the fulfillment of human rights. Previous research by, for example, Wachira and Smith [16], has found that the training and development of emergency medical services and fire services are of a high priority in developing countries. In the Balkhu settlement, psychosocial support is needed due to the background of its residents. As Shrestha states, control of disaster risk is part of the process of development.

\section{Conclusion}

Nepal, one of the poorest countries in the world, is vulnerable to various disasters and emergencies. Generally, a large number of achievements can be found in the planning of local level disaster preparedness. The results of women's empowerment and local level training in some communities in Nepal are encouraging. Still, in the Balkhu settlement, not much has been done for disaster preparedness. It is recommended that general awareness of disaster preparedness and training of residents be included as components of the ongoing development projects at the settlement.

\section{Acknowledgements}

I would like to convey my gratitude to Diaconia University of Applied Sciences and especially to Mr. Sami Kivelä, Project manager of GLORE project, all the participants and Ms. Marketta Fredriksson, Information Specialist, for their support and assistance. 


\section{References}

[1] E. Ablah, K.S. Konda, K. Konda, M. Melbourne, J. N. Ingoglia, K.M. Gebbie, Emergency preparedness training and response among community health centers and local health departments: Results from a multi-state survey. Journal of Community health, $35,3,2010$, pp. 285-293.

[2] P.C Karmacharya, G.K. Singh, M.P Singh, V.G Gautam, A. Par, A.K. Banskota, A. Bajracharya, A.B. Shreshtha, D. Mahara, Managing the injury burden in Nepal. Clin Orthop Relat Res., 466, 10, 2008, pp. 2343-2349.

[3] D. Zurick, A. Rose, Landscape Change in Kathmandu Valley, Nepal. American Geographical Society's Focus on Geography, 51, 4, 2009, pp. 7-16.

[4] A. Rademacher, When is housing an environmental problem? Reforming informality in Kathmandu, Curr. Anthropol, 50, 4, 2009, pp. 513-533.

[5] S. Doocy, E. Russell, Y. Gorokhovich, T. Kirsch, Disaster preparedness and humanitarian response in flood and landslide-affected communities in Eastern Uganda. Disaster Prevention and management, 22, 4, 2013, pp. 326-339.

[6] C.S. North, B. Pfefferbaum, Mental health response to community disasters. A systematic review. JAMA, 310, 5, 2013, pp. 507-518.

[7] L.B Filmer, J. Ranse, Who is my leader? A case study from a hospital disaster scenario in a less developed country. Australas Emerg Nurs J., 16, 2013, pp. 170-174.

[8] K. Shiwaku, R. Shaw, R.C. Kandel, S.N. Shrestha, A.M. Dixit, Future perspective of school disaster education in Nepal. Disaster Prevention \& Management, 16, 4, 2007, pp. 576-587.

[9] L. Acharya, K. D. Upadhya, F. Kortmann, Mental health and psychosocial support aspects in disaster preparedness: Nepal. International Review of Psychiatry, 18, 6, 2006, pp. 587-592.

[10] P. Bolton, W.A. Tol, J. Bass, Introduction to this special issue: Combining qualitative and quantitative research methods to support psychosocial and mental health programmes in complex emergencies. Intervention, 7, 3, 2009, pp. 181-186.

[11] B.A. Kohrt, Vulnerable social groups in postconflict settings: a mixed methods policy analysis and epidemiology study of caste and psychological morbidity in Nepal. Intervention, 7, 3, 2009, pp. 239-264.

[12] M. Sassene, P. Triantafillou, Psychosocial Rehabilitation and Democratic Development in Nepal. Journal for Cultural Research, 15, 1, 2011, pp. 35-54.

[13] S. Jones, K. Aryal, A. Collins, Local-level governance of risk and resilience in Nepal. Disasters, 37, 3, 2013, pp. 442-467.

[14] R. Dhungel, R.N. Ojha, Women's empowerment for disaster risk reduction and emergency response in Nepal. Gender \& Development, 20, 2, 2012, pp. 309-321.

[15] U. Syed, N. Khadka, A. Khan, S. Wall, Care-seeking practices in South Asia: using formative research to design program interventions to save newborn lives. Journal of Perinatology, 28, 2008, pp. S9-s13.

[16] B.W. Wachira, W. Smith, Major incidents in Kenya: the case for emergency services development and training. Prehospital and disaster medicine, 28, 2, 2013, pp. 170-173.

[17] H.D. Shrestha, Disaster risk management. Strategic focus is needed. From the reader. Newspaper article. The Himalaya 11.11.2014. 